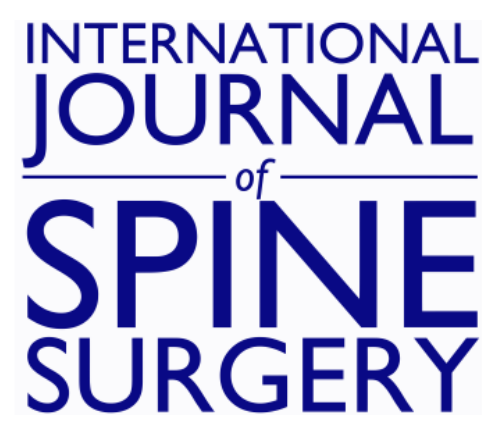

\title{
Risk of Cancer Following Lumbar Fusion Surgery With Recombinant Human Bone Morphogenic Protein-2 (rhBMP-2): An Analysis Using a Commercially Insured Patient Population
}

GREGORY S. COOPER and TZUYUNG DOUG KOU

Int J Spine Surg 2018, 12 (2) 260-268

doi: https://doi.org/10.14444/50323

http://ijssurgery.com/content/12/2/260

This information is current as of April 26, 2023.

Email Alerts Receive free email-alerts when new articles cite this article. Sign up at:

http://ijssurgery.com/alerts 


\title{
Risk of Cancer Following Lumbar Fusion Surgery With Recombinant Human Bone Morphogenic Protein-2 (rhBMP-2): An Analysis Using a Commercially Insured Patient Population
}

\author{
GREGORY S. COOPER, MD, ${ }^{1,2}$ TZUYUNG DOUG KOU, PhD ${ }^{1}$ \\ ${ }^{1}$ University Hospitals Cleveland Medical Center, Division of Gastroenterology, Cleveland, Ohio, ${ }^{2}$ Case Western Reserve University, Case Comprehensive Cancer \\ Center, Cleveland, Ohio
}

\begin{abstract}
Background: Recombinant human bone morphogenetic protein-2 (rhBMP-2) is frequently used to promote new bone growth after lumbar fusion surgery. However, because BMP receptors are found on cancer cells, there is concern about potential cancer following treatment with rhBMP-2. Data from clinical trials have reported divergent results and have been limited by small sample sizes and relatively short follow-up. We therefore examined the long-term risk of cancer following treatment with rhBMP-2 after lumbar fusion surgery.

Methods: Using the MarketScan Commercial Claims and Encounters database, we identified all patients $<65$ years without prior cancer who underwent lumbar fusion surgery between October 2003 and December 2009 and were followed at least 3 years after surgery. Development of any Surveillance Epidemiology and End Results malignancy in follow-up was identified through diagnosis and procedure codes.

Results: Among 39448 eligible patients, 2345 (5.9\%) received rhBMP at surgery; the median follow-up in this population was 4.87 years. Cancer in follow-up was observed in 49 BMP-treated patients $(0.43 / 100$ person years) and 1072 nontreated patients $(0.58 / 100$ person years). Use of rhBMP was associated with a cancer risk similar to that of untreated patients in both univariate (hazard ratio, 0.80; 95\%, CI 0.54-1.19) and multivariate proportional hazards analyses (hazard ratio, 0.81; 95\% CI, 0.54-1.20). Similar findings were observed in a secondary analysis after adjustment for likelihood of rhBMP administration.

Conclusions: In this retrospective cohort with at least 3 years of follow-up, administration of rhBMP during lumbar fusion surgery was not associated with an increased risk of subsequent cancer.

Level of Evidence: 4

Lumbar Spine

Keywords: human BMP-2 protein, spinal fusion, carcinogenesis, claims analysis, MarketScan data
\end{abstract}

\section{INTRODUCTION}

Bone morphogenic proteins (BMPs) are growth factors that are known, among other properties, to induce bone formation and thus have been evaluated as an alternative to iliac crest bone grafting at the time of fusion of the lumbar spine. ${ }^{1}$ Recombinant human BMP-2 (rhBMP-2) is indicated for anterior lumbar fusion and is administered via an absorbable collagen sponge carrier known as the Infuse Bone Graft (Medtronic Inc, Memphis, Tennessee). In addition, rhBMP-7 is available as a mixture with bovine collagen and after reconstitution with saline is administered as a paste. BMPs are thought to play a role in apoptosis as well as cell growth and differentiation, and receptors for BMP are found on multiple cell types, including cancer cells. ${ }^{2}$ A review of the preclinical literature concluded that whereas BMP-2 likely does not cause de novo cancers, it may have potential to enhance tumor function, and thus more definitive research is needed. ${ }^{3}$

Although randomized clinical trial data did not suggest any association of rhBMP with development of cancers, ${ }^{4,5}$ additional analyses of trial data found a greater frequency of malignancy in patients who received rhBMP compared with those who received bone grafts, ${ }^{6-8}$ with two analyses achieving statistical significance. ${ }^{7,8}$ In addition, observational studies using both Medicare ${ }^{9-11}$ and commercial insurance claims $^{12,13}$ data did not show an increased cancer risk, but they were limited by relatively short duration of follow-up after surgery and/or questions of generalizability to younger patients. A recently 
published study that used a linked tumor-Medicare database found no risk of second primary cancers or cancer recurrence, ${ }^{14}$ and a single-center study of over 500 patients also did not show an increased cancer incidence. ${ }^{15}$ Finally, a review ${ }^{16}$ of the clinical data found there was no conclusive evidence that rhBMP resulted in a higher risk of subsequent cancer but that the potential risk should be considered for each patient. However, because published studies typically had follow-up of 3 to 4 years and as little as under 2 years, ${ }^{13}$ delayed carcinogenic effects may not have been apparent.

Given the conflicting data about cancer risk, we performed a retrospective cohort study in a commercially insured population of patients less than 65 years of age, which would complement previous studies on the Medicare population ${ }^{9-11}$ and evaluate a population that was at lower baseline cancer risk. In addition, we restricted our analysis to patients with at least 3 years of follow-up. We hypothesized that the incidence of cancer in follow-up after surgery would be similar in the rhBMP-treated and untreated patients.

\section{METHODS}

\section{Database}

The Truven Health MarketScan Commercial Claims and Encounters database was established in 1988 and contains inpatient and outpatient records, with all patients purchasing insurance via large employers that are mostly self-insured. Since establishment, the database has included approximately 138 million unique, deidentified patients. Data are available for purchase directly from the vendor.

\section{Patients}

The cohort consisted of all patients between 18 and 65 years who underwent lumbar spine fusion between October 2003, which was when reimbursement was first provided for rhBMP administration, and December 2009. Data sources included claims from hospitals, physicians, ambulatory surgery centers, and institutional outpatient providers. Eligibility criteria included fusion of the lumbar spine as evidenced by the following International Classification of Diseases, Ninth Revision, Clinical Modification (ICD-9-CM) or Current Procedural Terminology, 4th Edition (CPT-4) codes: ICD-9-CM 81.06, 81.07, 81.08, 81.09, 81.36, 81.37, 81.38, CPT-
4 22558, 22630, 22612. Given potential for incomplete claims, patients were excluded if they were not listed in the MarketScan database for a minimum of 2 years before the surgery date. In order to exclude patients with prevalent cancers, as well as to differentiate newly diagnosed tumors from recurrence, we excluded all patients with a diagnosis code for cancer during the 24-month period prior to fusion, as well as patients with one or more $I C D-9$ $C M$ codes for "personal history of a malignant neoplasm" (V10.00-10.9) or at least one ICD-9-CM code for chemotherapy or radiation therapy.

As in previous studies, ${ }^{9,10}$ we identified exposure to rhBMP through the procedure code (ICD-9-CM 84.52) that was recorded on the lumbar fusion surgery date. Higher doses of rhBMP (ie, $>40 \mathrm{mg}$ ) have been proposed to be associated with an increased risk of cancer compared with lower doses. $^{8}$ Because rhBMP dose was not available in the database, we used indicator variables for two procedures more likely to be associated with higher doses, multiple level procedures, and refusion procedures.

\section{Measures}

The primary outcome was a diagnosis of any of the 26 malignant neoplasms included in the Surveillance Epidemiology and End Results (SEER) registries, ${ }^{17}$ and this was ascertained through the presence of at least one of the ICD-9-CM codes present in any files beginning at 3 years after the after the surgery date ${ }^{10}$ (Appendix). Thus, cancers that occurred within 3 years of surgery were not included. We used as a case definition $\geq 2$ codes for the same malignancy on different service dates and $\geq 1$ procedure code consistent with site-specific treatment (where applicable), chemotherapy, and/ or radiation therapy. This definition most closely approximated the standardized incidence ratio for any cancer in both the non-BMP and BMP-treated groups in a previous study. ${ }^{10}$

Other relevant variables included age in years (at the surgery date), gender, and length of follow-up. Data on race were not included in MarketScan files. To measure comorbidity, we used a previously validated, weighted index that included diagnoses contained in any of the files. ${ }^{18}$ In addition, as previously recommended to differentiate postoperative complications from preexisting comorbidities, ${ }^{18}$ we only included diagnoses that were 
contained in the files between 24 months and 30 days prior to the surgical date.

We followed all patients from 3 years after the surgical date through the earliest of cancer diagnosis (excluding cancers diagnosed within 3 years), death, disenrollment from the insurer, or end of the observation period (December 31, 2012).

\section{Analysis}

All analyses were performed using Statistical Analysis System, version 9 (SAS Inc, Cary, North Carolina). The primary analysis examined the association of demographics, comorbidities, and use of rhBMP with risk of any one of the SEER malignancies using the prespecified definition of 2 or more diagnoses on separate dates of service and evidence of treatment. Chi-square analysis was used to measure statistical significance. In order to account for different lengths of observation, Cox regression was used to evaluate the impact of rhBMP on development of individual SEER malignancies as well as overall cancer risk. Given the multiple comparisons and potential model overfitting, we used a Bonferroni correction when assessing statistical significance, which assigned a $P$ value of .0019 (eg, .05/26 sites) as significant. We compared the observed with expected cancer incidence in both groups using the expected gender- and age-specific incidence rates from SEER. We also constructed Kaplan-Meier curves to compare the risk of malignant neoplasms over time.

We then determined the association of rhBMP with risk of malignancy using multivariable Cox regression. As in univariate analysis, the primary analysis determined the association of rhBMP with overall cancer risk using the prespecified definition. In all models, we adjusted for demographics (age in years, gender if appropriate for that site) and comorbidity.

Due to the potential selection bias in treatment allocation, to further examine differences in longterm cancer risk we used propensity score adjustment. ${ }^{19,20}$ In this analysis, all variables potentially associated with use of rhBMP treatment decisions were included in a multivariable logistic model predicting likelihood of rhBMP therapy. By including all measurable factors that could affect rhBMP use, it is assumed that at least some of the nonmeasurable factors also track with these. Variables included age, gender, comorbidity score, year of surgery, geographic region, type of insurance, surgical approach, and use of a multilevel or redo procedure. The propensity score was then added as a covariate to the model, and risk of cancer was compared with the non-BMP group using Cox regression.

We also performed a secondary Cox regression analysis that was limited to patients who underwent multiple level procedures or redo procedures, both of which are associated with higher rhBMP dose.

The study protocol was approved by the local institutional review board.

\section{RESULTS}

From the MarketScan database, we identified 356306 patients who underwent lumbar spinal fusion. We then excluded 112164 patients with surgery before October 2003 or after December 2011; 124154 patients without continuous enrollment for at least 2 years prior to surgery; 47450 with less than 3 years of follow-up; 12890 with a history of cancer; and 20200 who were under 18 or over age 64 . The remaining 39448 patients were the subject of this analysis.

The characteristics of 39448 patients are shown in Table 1 . The mean age was $51.7 \pm 7.8$ years, $53.6 \%$ were women, $46.4 \%$ were men, and most patients had low comorbidity scores. There was evidence of rhBMP administration in 2345 patients $(5.9 \%)$. Compared with others, those who received rhBMP tended to be younger $(51.2 \pm 8.1$ years versus $51.7 \pm 7.7$ years, $P<.0001$ ), to be women, to have higher comorbidity indices, and were also more likely to undergo anterior procedures as well as multiple level or redo procedures. The use of rhBMP increased over the duration of the study. The mean and median length of follow-up were 4.90 and 4.87 years, respectively, in the rhBMP-treated patients (total of 11246 person years) and 5.00 and 5.04 years, respectively, in others (total of 187033 person years). All persons in both groups had a minimum of 3 years follow-up and a maximum of 9.2 years follow-up.

A cancer diagnosis in follow-up was observed in 1121 patients, corresponding to an incidence of $0.57 / 100$ person years. A total of 49 cancers were observed in the BMP-treated patients (incidence, $0.43 / 100$ person years) and 1072 in the nontreated patients $(0.58 / 100$ person years $)$. This corresponded to an incidence rate ratio of $0.75(95 \%$ CI, $0.56-$ 0.99), which indicates a slightly lower risk of cancer in the rhBMP-treated patients. Of note, in the age- 
Table 1. Cohort characteristics of BMP-treated and untreated patients.

\begin{tabular}{|c|c|c|c|c|c|c|c|}
\hline Characteristic & Total, $\mathbf{n}$ & $\%$ & BMP, n & $\%$ & No BMP, n & $\%$ & $P$ Value \\
\hline Age at surgery, y & & & & & & & $<.0001$ \\
\hline$<40$ & 3708 & 9.4 & 262 & 11.2 & 3446 & 9.3 & \\
\hline $40-49$ & 11200 & 28.4 & 659 & 28.1 & 10541 & 28.4 & \\
\hline $50-59$ & 18481 & 46.9 & 1077 & 45.9 & 17404 & 46.9 & \\
\hline $60-64$ & 6059 & 15.4 & 347 & 14.8 & 5712 & 15.4 & \\
\hline Gender & & & & & & & $<.0001$ \\
\hline Male & 18320 & 46.4 & 988 & 42.1 & 17332 & 46.4 & \\
\hline Female & 21128 & 53.6 & 1357 & 57.9 & 19771 & 53.3 & \\
\hline Comorbidity score & & & & & & & $<.0001$ \\
\hline 0 & 29314 & 74.3 & 1502 & 64.1 & 27812 & 75.0 & \\
\hline 1 & 9491 & 24.1 & 787 & 33.6 & 8704 & 23.5 & \\
\hline$\geq 2$ & 643 & 1.6 & 56 & 2.4 & 587 & 1.6 & \\
\hline Surgery date & & & & & & & $<.0001$ \\
\hline 2003 & 456 & 1.2 & 12 & 0.5 & 444 & 1.2 & \\
\hline 2004 & 4323 & 11.0 & 199 & 8.5 & 4124 & 11.1 & \\
\hline 2005 & 5150 & 13.1 & 316 & 13.5 & 4834 & 13.0 & \\
\hline 2006 & 6868 & 17.4 & 372 & 15.9 & 6496 & 17.5 & \\
\hline 2007 & 6469 & 16.4 & 391 & 16.7 & 6078 & 16.4 & \\
\hline 2008 & 7969 & 20.2 & 524 & 22.4 & 7445 & 20.1 & \\
\hline 2009 & 8213 & 20.8 & 531 & 22.6 & 7682 & 20.7 & \\
\hline \multicolumn{8}{|l|}{ Approach } \\
\hline Anterior & 3135 & 8.0 & 450 & 19.2 & 2685 & 7.2 & $<.0001$ \\
\hline Posterior or lateral transverse & 36313 & 92.1 & 1895 & 80.8 & 34418 & 92.8 & \\
\hline Multiple levels & 10846 & 27.5 & 1038 & 44.3 & 9808 & 26.4 & $<.0001$ \\
\hline Refusion & 829 & 2.1 & 83 & 3.5 & 746 & 2.0 & $<.0001$ \\
\hline
\end{tabular}

Abbreviation: BMP, bone morphogenic protein.

and gender-matched general population, the inci- Hodgkins lymphoma, melanoma, lung, prostate, dence rate is $0.45 / 100$ person years. The incidence of individual cancers by site is shown in Table 2. The most frequently observed sites were breast, non- myeloma, renal, and colorectal cancers. Although the incidence of lung cancer was somewhat higher in the rhBMP-treated patients $(0.04 / 100$ versus $0.02 /$

Table 2. Incidence of malignant neoplasia in BMP-treated and untreated patients.

\begin{tabular}{|c|c|c|c|c|c|c|}
\hline \multirow[b]{2}{*}{ Tumor Type } & \multirow[b]{2}{*}{$\mathbf{n}$} & \multirow[b]{2}{*}{ Incidence (/100 py) } & \multicolumn{2}{|c|}{ BMP Treated } & \multicolumn{2}{|c|}{ BMP Untreated } \\
\hline & & & $\mathbf{N}$ & Incidence (/100 py) & $\mathbf{N}$ & Incidence (/100 py) \\
\hline Any & 1121 & 0.57 & 49 & 0.43 & 1072 & 0.58 \\
\hline Bone & 0 & 0.00 & 0 & 0.00 & 0 & 0.00 \\
\hline Brain and $\mathrm{CNS}$ & 34 & 0.02 & 0 & 0.00 & 34 & 0.02 \\
\hline Breast & 217 & 0.20 & 7 & 0.11 & 210 & 0.21 \\
\hline Cervix uteri & 8 & 0.01 & 0 & 0.00 & 8 & 0.10 \\
\hline Colon and rectum & 74 & 0.04 & 2 & 0.02 & 72 & 0.04 \\
\hline Corpus uteri & 31 & 0.03 & 0 & 0.00 & 31 & 0.03 \\
\hline Esophagus & 8 & 0.00 & 0 & 0.00 & 8 & 0.00 \\
\hline Hodgkins lymphoma & 31 & 0.03 & 2 & 0.02 & 29 & 0.02 \\
\hline Non-Hodgkins lymphoma & 188 & 0.09 & 7 & 0.06 & 181 & 0.10 \\
\hline Kaposi sarcoma & 3 & 0.00 & 0 & 0.00 & 3 & 0.00 \\
\hline Kidney and renal pelvis & 62 & 0.03 & 3 & 0.03 & 59 & 0.03 \\
\hline Larynx & 2 & 0.00 & 0 & 0.00 & 2 & 0.00 \\
\hline Leukemia & 71 & 0.04 & 3 & 0.03 & 68 & 0.04 \\
\hline Liver and intrahepatic bile duct & 11 & 0.01 & 0 & 0.00 & 11 & 0.01 \\
\hline Lung and bronchus & 39 & 0.02 & 4 & 0.04 & 35 & 0.02 \\
\hline Melanoma & 114 & 0.06 & 7 & 0.06 & 107 & 0.06 \\
\hline Mesothelioma & 0 & 0.00 & 0 & 0 & 0 & 0.00 \\
\hline Myeloma & 80 & 0.04 & 4 & 0.04 & 76 & 0.04 \\
\hline Oral cavity and pharynx & 21 & 0.01 & 0 & 0.00 & 21 & 0.01 \\
\hline Ovary & 23 & 0.02 & 1 & 0.02 & 22 & 0.02 \\
\hline Pancreas & 18 & 0.01 & 0 & 0 & 18 & 0.01 \\
\hline Prostate & 93 & 0.10 & 5 & 0.10 & 88 & 0.10 \\
\hline Stomach & 12 & 0.01 & 0 & 0.00 & 12 & 0.01 \\
\hline Testis & 4 & 0.00 & 0 & 0.00 & 4 & 0.00 \\
\hline Thyroid & 62 & 0.03 & 3 & 0.03 & 59 & 0.03 \\
\hline Urinary bladder & 40 & 0.02 & 2 & 0.02 & 38 & 0.02 \\
\hline
\end{tabular}

Abbreviations: BMP, bone morphogenic protein; CNS, central nervous system; py, person year. 


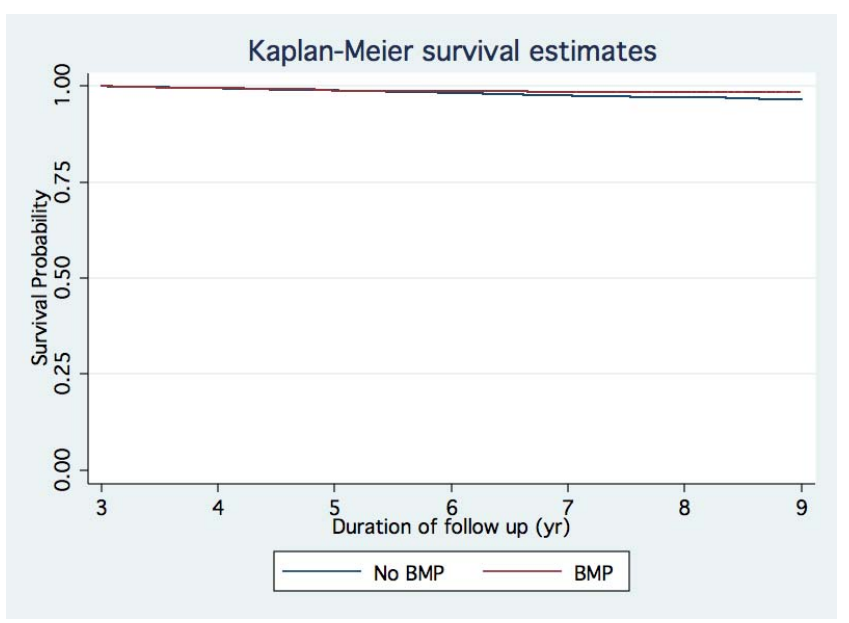

Figure. Kaplan-Meier plot of malignant neoplasia risk in recombinant human bone morphogenic protein (rhBMP)-treated and untreated patients. Through a follow-up period of up to 8 years, patients receiving rhBMP were at similar risk to receive a cancer diagnosis as untreated patients $(P=.2687$ by log-rank test).

100 person years), the difference was not statistically significant $(P=.13)$, and the incidence of other cancer types in rhBMP-treated patients never exceeded that of others. In a Kaplan-Meier analysis (Figure), patients who received rhBMP were at a risk for cancer development that was similar to those who did not $(P=.2687$ by log-rank test).

We also compared the observed with expected incidence of malignant neoplasms in an age- and gender-matched population according to SEER data. The standardized incidence ratio for the entire sample was $0.80(95 \% \mathrm{CI}, 0.74-0.87)$. For patients treated with rhBMP, the standardized incidence ratio was $0.42(95 \% \mathrm{CI}, 0.30-0.58)$, compared with a standardized incidence ratio of $0.83(95 \% \mathrm{CI}$, 0.77-0.90) in others. These findings indicate a somewhat lower cancer risk in both groups compared with the general population, but especially in the BMP treated patients.

We then used proportional hazards models to examine the association of rhBMP with cancer risk. For all cancers combined, use of rhBMP was associated with a similar risk of cancer in both univariate (hazard ratio [HR], 0.80; 95\% CI, 0.54$1.19, P=.276)$ and mulitivariate analyses (HR, 0.81 ; 95\% CI, 0.54-1.20, $P=.283$ ). Other factors associated with cancer risk in multivariate analysis included older age (ages 40-49 years: HR, 1.50; 95\% CI, $1.01-2.23, P=.05$; ages $50-59$ years: HR, 2.78; 95\% CI, 1.91-4.06, $P<.0001$; ages 60-64 years: HR, 12.02; 95\% CI, 7.53-19.20; $P<.0001$ compared with ages 18-39 years) and increased comorbidity score (1 comorbidity HR, 1.46; 95\% CI, 1.23-1.73, $P<.0001, \geq 2$ comorbidities HR, $1.12 ; 95 \%$ CI, $0.60-2.09, P=.730$ ). Data for individual sites are shown in Table 3. In both

Table 3. Proportional hazards models to risk of malignant neoplasms associated with BMP treatment.

\begin{tabular}{|c|c|c|c|c|c|c|c|c|}
\hline Site of Cancer & $\begin{array}{c}\text { Univariate } \\
\text { HR for rhBMP }\end{array}$ & $\begin{array}{l}\text { Lower } \\
95 \% \mathrm{CI}\end{array}$ & $\begin{array}{l}\text { Upper } \\
95 \% \mathrm{CI}\end{array}$ & $P$ Value & $\begin{array}{c}\text { Multivariate } \\
\text { HR for rhBMP }\end{array}$ & $\begin{array}{l}\text { Lower } \\
95 \% \mathrm{CI}\end{array}$ & $\begin{array}{l}\text { Upper } \\
95 \% \text { CI }\end{array}$ & $P$ Value \\
\hline Bone & 0 & 0 & 0 & & 0 & 0 & 0 & \\
\hline Brain and other central nervous system & 0.22 & 0.03 & 1.61 & .138 & 0.26 & 0.04 & 1.92 & .188 \\
\hline Breast & 0.79 & 0.48 & 1.31 & .359 & 0.86 & 0.52 & 1.43 & .560 \\
\hline Cervix uteri & 0.00 & 0.00 & - & .992 & 0.00 & 0.00 & - & .991 \\
\hline Colon and rectum & 0.72 & 0.32 & 1.64 & .438 & 0.90 & 0.39 & 2.05 & .794 \\
\hline Corpus uteri & 0.29 & 0.04 & 2.12 & .223 & 0.29 & 0.04 & 2.14 & .226 \\
\hline Esophagus & 0.00 & 0.00 & - & .990 & 0.00 & 0.00 & - & .994 \\
\hline Hodgkins lymphoma & 1.23 & 0.38 & 3.99 & .733 & 1.24 & 0.38 & 4.08 & .725 \\
\hline Non-Hodgkins lymphoma & 0.72 & 0.43 & 1.22 & .222 & 0.72 & 0.43 & 1.22 & .218 \\
\hline Kaposi sarcoma & 0.00 & 0.00 & - & .993 & 0.00 & 0.00 & - & .996 \\
\hline Kidney and renal pelvis & 0.78 & 0.34 & 1.76 & .543 & 0.71 & 0.31 & 1.62 & .414 \\
\hline Larynx & 0.00 & 0.00 & - & .997 & 0.00 & 0.00 & - & .999 \\
\hline Leukemia & 0.77 & 0.34 & 1.75 & .530 & 0.65 & 0.28 & 1.48 & .301 \\
\hline Liver and intrahepatic bile duct & 0.00 & 0.00 & - & .990 & 0.00 & 0.00 & - & .994 \\
\hline Lung and bronchus & 1.18 & 0.47 & 2.95 & .719 & 1.05 & 0.42 & 2.65 & .913 \\
\hline Melanoma & 0.72 & 0.37 & 1.41 & .336 & 0.70 & 0.36 & 1.38 & .302 \\
\hline Mesothelioma & 0.00 & 0.00 & - & .997 & 0.00 & 0.00 & - & .999 \\
\hline Myeloma & 0.70 & 0.33 & 1.50 & .358 & 0.64 & 0.30 & 1.38 & .254 \\
\hline Oral cavity and pharynx & 0.59 & 0.08 & 4.33 & .601 & 0.67 & 0.09 & 5.03 & .699 \\
\hline Ovary & 0.71 & 0.17 & 2.96 & .643 & 0.72 & 0.17 & 3.05 & .660 \\
\hline Pancreas & 0.00 & 0.00 & - & .984 & 0.00 & 0.00 & - & .990 \\
\hline Prostate & 0.74 & 0.35 & 1.58 & .433 & 0.72 & 0.33 & 1.54 & .394 \\
\hline Stomach & 0 & 0.00 & & .988 & 0.00 & 0.00 & & .992 \\
\hline Testis & 1.94 & 0.24 & 15.80 & .536 & 2.03 & 0.24 & 17.48 & .519 \\
\hline Thyroid & 0.53 & 0.17 & 1.68 & .282 & 0.50 & 0.16 & 1.60 & .245 \\
\hline Urinary bladder & 0.51 & 0.13 & 2.10 & .353 & 0.58 & 0.14 & 2.40 & .453 \\
\hline
\end{tabular}

Abbreviations: HR, hazard ratio; rhBMP, recombinant human bone morphogenic protein. Dashes in cells indicate that that the confidence interval could not be estimated because of sample size. 
univariate and multivariate analyses, there was no association of rhBMP use with risk of any of the malignant neoplasms, though for many sites, the infrequent number of events precluded the calculation of reliable estimates.

In order to adjust for potential selection bias in rhBMP treatment allocation, we developed a propensity score to predict the probability of receipt of rhBMP. The propensity score had good discrimination in predicting the likelihood of receiving rhBMP, as evidenced by a receiver operating characteristic curve area of 0.810 , which indicates a much better likelihood of prediction than by chance alone (0.50). After adjustment for the propensity score, the use of rhBMP was associated with a similar risk of malignant neoplasia as that of untreated patients (HR, 0.76; 95\% CI, 0.51-1.14). Finally, we performed a secondary proportional hazards model that was limited to patients who underwent multiple level or redo procedures, which are often associated with higher rhBMP doses. In this cohort, the multivariate $\mathrm{HR}$ for rhBMP exposure was $0.71(95 \% \mathrm{CI}, 0.46-1.11 ; P=.134)$ and thus not associated with cancer risk.

\section{DISCUSSION}

The effect of rhBMP on cancer risk is controversial. Although a meta-analysis failed to demonstrate increased risk of malignant tumors with rhBMP, ${ }^{21} \mathrm{a}$ tumor-promotion effect of rhBMP cannot be excluded on a molecular level. ${ }^{3}$ In the current study, which included a relatively long duration of followup, we did not demonstrate any cancer risk associated with rhBMP administration. The findings were robust when we attempted to adjust for confounding factors, including the likelihood of receiving $\mathrm{rhBMP}$, as well as when restricted to indications that may be associated with higher rhBMP doses. The observed cancer incidence $(0.43$ case/100 person years versus 0.58 case/100 person years in non-BMP patients) was lower than in studies that included a Medicare-aged population (1.7-2.1 cases/100 person years $)^{11,14}$ and in the same range as in non-BMP-treated patients from clinical trial data $(0.50$ case $/ 100$ person years $) .{ }^{8}$ The latter study $^{8}$ also found a much higher incidence in BMPtreated patients (3.37 cases/100 person years).

Receptors for BMP are found on a variety of cancer cells, ${ }^{2}$ and thus there is potential concern for BMP in the promotion of tumor growth both locally and at metastatic sites. Although at the cellular level, BMP has been shown to promote angiogenesis, ${ }^{22,23}$ cell growth, ${ }^{24}$ bone metastases, ${ }^{25}$ and malignant cell motility and invasiveness, ${ }^{26} \mathrm{BMP}$ is also capable of inhibiting proliferation and growth and thus could have potential antineoplastic effects. $^{25,26}$ However, given at least the potential concern for BMP promoting progression, rhBMP is not indicated in the vicinity of a resected or extant cancer or in those receiving treatment for malignancy. ${ }^{27}$

The methodology and data sources that we used have several strengths and limitations. Our study had a very large sample and consisted of a wide range of practices and captured multiple cancer diagnoses. The data were limited by the absence of clinical detail, including factors such as smoking, alcohol use, obesity, family history of cancer, and differences in intraoperative technique that may have been associated with rhBMP use and/or cancer risk. However, consistent results were observed in an analysis that included a propensity score for likelihood of rhBMP administration. Also, in a previous study ${ }^{9}$ of pancreatic carcinoma after rhBMP exposure, medical record review found no association of rhBMP with other cancer risk factors such as obesity and smoking. We also could not rule out differences in treatment allocation, although patients at increased cancer risk at baseline were preferentially not given rhBMP. In addition, although the patients receiving rhBMP were somewhat younger and therefore at lower baseline cancer risk, the differences were maintained after adjustment for age as well as gender and comorbidity. We also could not measure the actual rhBMP dose, but in analyses limited to procedures typically associated with higher doses, there was no association with malignancy. Although the follow-up was at least 3 years after surgery, with some patients followed as long as 8 years, if the potential risk of rhBMP is mutagenesis rather than tumor promotion, an even longer follow-up period may be required to definitively exclude its malignant potential. We also ascertained previous and subsequent cancers through the use of $I C D-9-C M$ codes, which were developed for reimbursement and not for research. However, the algorithm that was used included fairly stringent criteria to define the presence of malignant tumors. Our study was limited to lumbar fusion procedures in adult patients. We recognize that the product is not uncommonly used off label and therefore included posterior or transverse 
procedures, neither of which were approved indications. However, we did exclude patients with contraindications to BMP including age $<18$ years or previous cancer diagnoses, and no women in the sample were known to be pregnant. Despite the large sample, we did not have sufficient power to detect any differences in the incidence of rare tumors and did not capture neoplasms not contained in SEER such as nonmelanoma skin cancers. Finally, because we used a procedure code as a measure of rhBMP administration, there is the potential for misclassification. However, in previous work, ${ }^{9}$ the specificity of the procedure code for receipt of rhBMP-2 (compared with rhBMP-7) was $95 \%$ and the positive predictive value of the code was $100 \%$.

\section{CONCLUSIONS}

In this large sample of commercially insured patients, we found that treatment with rhBMP during fusion of the lumbar spine did not increase the subsequent risk of cancer. Although some previous studies did show an increased cancer risk, the findings of this and other database studies should provide reassurance to both patients and providers.

\section{REFERENCES}

1. Rihn JA, Gates C, Glassman SD, Phillips FM, Schwender JD, Albert TJ. The use of bone morphogenic protein in lumbar spine surgery. J Bone Joint Surg Am. 2008;90(9):2014-2025.

2. Thawani JP, Wang AC, Than KD, Lin CY, LaMarca F, Park D. Bone morphogenic proteins and cancer: review of the literature. Neurosurgery. 2010;66(2):233-246.

3. Skovrlj B, Koehler SM, Anderson PA, et al. Association between BMP-2 and carcinogenicity. Spine (Phila Pa 1976). 2015;40(23):1862-1871.

4. Benglis D, Wang MY, Levi AD. A comprehensive review of the safety profile of bone morphogenic protein in spine surgery. Neurosurgery. 2008;62(5 suppl 2):ONS423ONS431.

5. Poynton AR, Lane JM. Safety profile for the clinical use of bone morphogenic proteins in the spine. Spine (Phila $\mathrm{Pa}$ 1976). 2002;27(16 suppl 1):S40-S48.

6. Simmonds MC, Brown JVE, Heirs MK, et al. Safety and effectiveness of recombinant human bone morphogenic protein2 for spinal fusion. Ann Intern Med. 2013;158(12):877-889.

7. Fu R, Selph S, McDonagh M, et al. Effectiveness and harms of recombinant human bone morphogenic protein-2 in spine fusion. Ann Intern Med. 2013;158(12):890-902.

8. Carragee EJ, Chu G, Rohatgi R, et al. Cancer risk after use of recombinant bone morphogenic protein-2 for spinal arthrodesis. J Bone Joint Surg Am. 2013;95(17):1537-1545.
9. Mines D, Gu Y, Kou TD, Cooper GS. Recombinant human bone morphogenic protein-2 and pancreatic cancer: a retrospective cohort study. Pharmacoepidemiol Drug Saf. 2011;20(2):111-118.

10. Cooper GS, Kou TD. Risk of cancer following lumbar fusion surgery with recombinant human bone morphogenic protein-2 (rh-BMP-2). Spine (Phila Pa 1976). 2013;38(21):1862-1868.

11. Kelly MP, Savage JW, Bentzen SM, Hsu WK, Ellison SA, Anderson PA. Cancer risk from bone morphogenic protein exposure in spinal arthrodesis. $J$ Bone Joint Surg Am. 2014;96(17):1417-1422.

12. Lad SP, Bagley JH, Karikari IO, et al. Cancer after spinal fusion: the role of bone morphogenic protein (BMP). Neurosurgery. 2013;73(3):440-449.

13. Veeravagu A, Cole TS, Jiang B, Ratliff JK, Gidwani RA. The use of bone morphogenic protein in thoracolumbar spine procedures: analysis of the MarketScan longitudinal database. Spine J. 2014;14(12):2929-2937.

14. Beachler DC, Yanik EL, Martin BI, et al. Bone morphogenetic protein use and cancer risk among patients undergoing lumbar arthrodesis. J Bone Joint Surg Am. 2016;98(13):1064-1072.

15. Malham GM, Giles GG, Milne RL, Blecher CM, Brazenor GA. Bone morphogenic proteins in spinal surgery. What is the fusion rate and do they cause cancer? Spine (Phila Pa 1976). 2015;40(22):1737-1742.

16. Cahill KS, McCormick PC, Levi AD. A comprehensive assessment of the risk of bone morphogenic protein use in spinal fusion surgery and postoperative cancer diagnosis. $J$ Neurosurg Spine. 2015;23(1):86-93.

17. Howlader N, Noone AM, Krapcho M, et al, eds. SEER Cancer Statistics Review, 1975-2012, National Cancer Institute. Bethesda. http://seer.cancer.gov/csr/1975_2012/, based on November 2014 SEER data submission posted to the SEER website April 2015. Accessed November 8, 2016.

18. Klabunde CN, Warren JL, Legler JM. Assessing comorbidity using claims data. Med Care. 2002;40(8 suppl):2635.

19. Rosenbaum PR, Rubin DB. Reducing bias in observational studies using subclassification on the propensity score. $J$ Am Stat Assoc. 1984;79(387):516-524.

20. D'Agostino RB. Tutorial in biostatistics: propensity score methods for bias reduction in the comparison of a treatment to a non-randomized control group. Stat Med. 1998;17(19): 2265-2281.

21. Vavken J, Mameghani A, Vavken P. Schaeren S. Complications and cancer rates in spine fusion with recombinant human bone morphogenic protein-2 (rhBMP-2). Eur Spine J. 2016;25(12):3979-3989.

22. Langenfeld EM, Langenfeld J. Bone morphogenic protein-2 stimulates angiogenesis in developing tumors. Mol Cancer Res. 2004; 2(3):141-149.

23. Bieniasz M, Oszajca K, Eusebio M, Kordiak J, Bortkowiak J, Szemra J. The positive correlation between gene expression of the two angiogenic factors: VEGF and BMP-2 in lung cancer patients. Lung Cancer. 2009;66(3):319-326.

24. Kleeff J, Maruyama $\mathrm{H}$, Ishiwata $\mathrm{T}$, et al. Bone morphogenic protein 2 exerts diverse effects on cell growth in vitro and is expressed in human pancreatic cancer in vivo. Gastroenterology. 1999;116(5):1202-1216. 
25. Singh A, Morris RJ. The yin and yang of bone morphogenic proteins in cancer. Cytokine Growth Factor Rev. 2010;21(4):299-313.

26. Soda H, Raymond E, Sharma S, et al. Antiproliferative effects of recombinant human bone morphogenic protein-2 on human tumor colony-forming units. Anticancer Drugs. 1998;9(4):327-331.

27. Infuse Bone Graft. Brief summary of indications, contraindications and warnings. https://www.infusebonegraft. com/infuse-indications.html. Accessed November 8, 2016.

Disclosures and COI: The study was funded by a research grant from Medtronic, Inc. The sponsor had no role in the design of the study or content of the manuscript. Neither author had any financial interest in Medtronic. Dr Cooper is also supported by grant P30-CA43703 to the Case Comprehensive Cancer Center and grant
UL1TR000439 from the National Center for Advancing Translational Sciences.

Corresponding author: Gregory S. Cooper, MD, Division of Gastroenterology, University Hospitals Cleveland Medical Center, 11100 Euclid Avenue, Wearn 244, Cleveland, OH 44106-5066. Phone: (216) 844-5385; Email: Greg.cooper@case. edu.

Published 3 August 2018

This manuscript is generously published free of charge by ISASS, the International Society for the Advancement of Spine Surgery. Copyright (C) 2018 ISASS. To see more or order reprints or permissions, see http://ijssurgery.com. 
Appendix. Cancer diagnosis and procedure codes.

\begin{tabular}{|c|c|c|c|}
\hline Type of Malignant Tumor & ICD-9-CM Diagnosis Codes & ICD-9-CM Procedure Codes & $C P T-4$ Procedure Codes \\
\hline Bone & $170.0-170.9$ & $84.0-84.19$ & $\begin{array}{l}23900-23921,24900-24940,25900- \\
25931,26910-26952,27290,27295 \\
27590-27598,27880-27889,28800- \\
28825\end{array}$ \\
\hline Brain and other central nervous system & 191.0-192.3 & 01.1-01.59 & $\begin{array}{l}61510,61516,61518,61520,61521 \\
\quad 61524,61526,61530,61534,61536 \\
61544,61545\end{array}$ \\
\hline Breast & $174.0-175.9$ & $84.4-85.48,85.20-85.23$ & $\begin{array}{l}19120,19125,19126,19160,19162, \\
\quad 19180-19240\end{array}$ \\
\hline Cervix uteri & 180.0-180.9 & $68.3-68.9$ & $\begin{array}{l}57530,57531,58150,58180,58200, \\
\quad 58210,58240,58260,58262,58275, \\
58285,58940\end{array}$ \\
\hline Colon and rectum & $153.0-154.8$ & $\begin{array}{l}45.71-45.79,45.8,48.5 \\
\quad 48.62,48.63\end{array}$ & $\begin{array}{c}44140,44141,44143,44144,44145- \\
44147,44150-44153,44155,44156 \\
44160,45110-45114,45116,45119\end{array}$ \\
\hline Corpus uteri & $179,182.0-182.8$ & $68.3-68.9$ & $\begin{array}{l}58150,58180,58200,58210,58240 \\
58260,58262,58275,58285,58940\end{array}$ \\
\hline Esophagus & $150.0-150.9$ & $42.4-42.69$ & $43107-43124$ \\
\hline Hodgkins lymphoma & 201.0-201.9 & $\begin{array}{l}\text { Chemotherapy and } / \text { or } \\
\text { radiation therapy }\end{array}$ & $\begin{array}{l}\text { Chemotherapy and/or radiation } \\
\text { therapy }^{\text {a }}\end{array}$ \\
\hline Non-Hodgkins lymphoma & $200.0-200.8,202.0-202.9$ & $\begin{array}{l}\text { Chemotherapy and/or } \\
\text { radiation therapy }\end{array}$ & $\begin{array}{l}\text { Chemotherapy and/or radiation } \\
\text { therapy }^{\text {a }}\end{array}$ \\
\hline Kaposi sarcoma & $176.0-176.9$ & $\begin{array}{l}\text { Chemotherapy and } / \text { or } \\
\text { radiation therapy }^{\text {a }}\end{array}$ & $\begin{array}{l}\text { Chemotherapy and/or radiation } \\
\text { therapy }^{\text {a }}\end{array}$ \\
\hline Kidney and renal pelvis & 189.0-189.9 & $55.4-55.54,56.4-56.51$ & $50220-50240,50650,50660$ \\
\hline Larynx & 161.0-161.9 & $25.2-25.4,29.33,30.1-30.4$ & $\begin{array}{l}31360-31420,41120-41155,42120 \\
\quad 42410-42426\end{array}$ \\
\hline Leukemia & 205.0-208.9 & $\begin{array}{l}\text { Chemotherapy and } / \text { or } \\
\text { radiation therapy }\end{array}$ & $\begin{array}{l}\text { Chemotherapy and/or radiation } \\
\text { therapy }^{\text {a }}\end{array}$ \\
\hline Liver and intrahepatic bile duct & $155.0-155.2,156.0-156.9$ & $50.22,50.3,50.4,51.36$ & $\begin{array}{l}47120-47130,47711,47712,47760, \\
47765,47780,47785,47800\end{array}$ \\
\hline Lung and bronchus & $162.0-163.9$ & $\begin{array}{l}32.29,32.3,32.4,32.5,32.6 \\
\quad 32.9\end{array}$ & $\begin{array}{l}47120-47130,47711,47712,47760, \\
\quad 47765,47780,47785,47800\end{array}$ \\
\hline Melanoma & $172.0-172.9$ & $86.24,86.4$ & $\begin{array}{l}11600-11646,17260-17286,17304- \\
17310\end{array}$ \\
\hline Mesothelioma & 163.0-163.9 & $\begin{array}{l}32.29,32.3,32.4,32.5,32.6 \\
\quad 32.9\end{array}$ & $\begin{array}{l}32440,32442,32445,32480,32482, \\
32484,32486,32488,32500,32520, \\
32522,32525,32657,32663\end{array}$ \\
\hline Myeloma & $203.0,238.6$ & $\begin{array}{l}\text { Chemotherapy and } / \text { or } \\
\text { radiation therapy }\end{array}$ & $\begin{array}{l}\text { Chemotherapy and/or radiation } \\
\text { therapy }^{\text {a }}\end{array}$ \\
\hline Oral cavity and pharynx & 140.0-149.9 & $25.2-25.4,29.33,30.1-30.4$ & $\begin{array}{l}31360-31420,41120-41155,42120, \\
\quad 42410-42426\end{array}$ \\
\hline Ovary & $183.0-183.9$ & $\begin{array}{l}65.0,65.4,65.5,65.6,68.3- \\
\quad 68.9\end{array}$ & $\begin{array}{l}58150,58180,58200,58210,58240, \\
\quad 58260,58262,58275,58285,58940, \\
58943,58950-58952,58960\end{array}$ \\
\hline Pancreas & $157.0-157.3,157.8,157.9$ & $\begin{array}{l}44.39,51.36,51.39,51.42 \\
52.50-52.79 ; 6\end{array}$ & $\begin{array}{l}43820,43825,47720-47790,48140- \\
\quad 48144,48146,48147,48149-48155\end{array}$ \\
\hline Prostate & 185 & $60.5,62.4-62.42$ & $\begin{array}{l}54520,54530,55810-55815,55840- \\
\quad 55845\end{array}$ \\
\hline Stomach & 151.0-151.9 & $42.5-43.99$ & $43620-43634,43638$ \\
\hline Testis & 186.0-186.9 & $62.3,62.4$ & $54520,54535,54690$ \\
\hline Thyroid & 193 & $06.11-06.12,06.2-06.52$ & $60210-60271$ \\
\hline Urinary bladder & $188.0-188.9$ & $\begin{array}{l}57.33,57.4,57.49,57.71 \\
\quad 57.79\end{array}$ & $\begin{array}{l}51570,51575,51580-51597,51720 \\
\quad \text { J8520, J8521 }\end{array}$ \\
\hline
\end{tabular}

Abbreviations: International Classification of Diseases, Ninth Revision, Clinical Modification (ICD-9-CM) or Current Procedural Terminology, 4th Edition (CPT-4). ${ }^{a}$ Chemotherapy defined by $I C D-9-C M$ codes 99.25, V58.1, V66.2, or V67.2, CPT-4 codes 96400-96549, J9000-J9999, and Q0083-Q0085 and revenue center codes of 0331, 0332, and 0335. Radiation therapy was defined by $I C D-9-C M$ diagnosis codes V58.0, V 66.1 and V 67.1, ICD-9-CM procedure codes $92.2-92.39, C P T-4$ codes of 77261$77431,77499,77750-77799$ and revenue center codes of 0330 and 0333. 